\title{
Postural Analysis of a Developing Country's Municipal Solid Waste Handlers and a Reference Group of Hospital General Hands using the RULA Method
}

\author{
France Ncube ${ }^{1}$, Esper J. Ncube ${ }^{1} \&$ Kuku Voyi ${ }^{1}$ \\ ${ }^{1}$ School of Health Systems and Public Health, Faculty of Health Sciences, University of Pretoria, South Africa \\ Correspondence: France Ncube, School of Health Systems and Public Health, Faculty of Health Sciences, \\ University of Pretoria, Pretoria, South Africa. Tel: 277-81-321-247. E-mail: france.ncube257@gmail.com
}

Received: August 12, 2017 Accepted: September 12, $2017 \quad$ Online Published: September 18, 2017

doi:10.5539/gjhs.v9n10p194 URL: https://doi.org/10.5539/gjhs.v9n10p194

\begin{abstract}
Background: Municipal solid waste handlers perform various work activities which may contribute to the onset of work-related musculoskeletal disorders (WRMDs). This study conducted a postural analysis of these workers and a reference group of hospital general hands in order to identify unsafe working postures requiring correction.
\end{abstract}

Methods: The Rapid Upper Limb Assessment (RULA) methodology was used for postural analysis to 30 municipal solid waste handlers (MSWHs) and a reference group of 30 hospital general hands (HGHs) involved in similar work activities. Field observations and photography were used to collect data. Collected data was analysed using STATA version 13.

Results: The Mann-Whitney test was used to compare the two groups. Results showed significant differences ( $p<$ 0.05 ) for lifting, carrying and emptying activities. For both groups, the mean postural scores for pushing, pulling and standing activities were mainly in the low risk category and not statistically significant $(\mathrm{p}>0.05)$.

Conclusion: Results of the present study show unsafe RULA postural scores to MSWHs with regard to lifting, carrying and emptying of refuse bins. Such scores are suggestive of an elevated risk to developing WRMDs in these workers compared to the reference group.

Keywords: municipal solid waste handlers, musculoskeletal disorders, postural assessment, RULA

\section{Introduction}

Poor working postures have been associated with an elevated of developing WRMDs (Ariëns et al., 2001; Liu, Chen, Wang, \& Hang, 2004; Kaliniene et al., 2016; Howarth et al., 2016). The activities performed in poor working postures have been richly investigated in occupations such as dentistry (Valachi \& Valachi, 2003; Alexopoulos, Stathi, \& Charizani, 2004; Howarth et al., 2016), computer work (Liu, Chen, Wang, \& Hang, 2003; Malińska M \& Bugajska, 2010; Kaliniene et al., 2016) and agriculture (Rosecrance, Rodgers, \& Merlino, 2006; Holmberg, Thelin, Stiernström, \& Svärdsudd, 2003). Such efforts assist in the identification of the poor postures requiring correction in the given occupations. In contrast, very few of such investigations have focused on MSWHs. The few available studies are mostly from developed countries (Hoozemans et al., 2004; Kuijer et al., 2003), with almost none from the developing world. In the Netherlands, Hoozemans and colleagues focused on pushing and pulling of refuse carts and estimated the loading of the low back and joints at the shoulder using biomechanical models. This dimension appears crucial with regards to estimating the ergonomic impact of measures on the pulling and pushing activities (Hoozemans et al., 2004). Similarly, Kuijer and colleagues used advanced biomechanical models to study the mechanical and perceived workload with regard to pushing and pulling a redesigned refuse cart.

In the present article the focus, scope and method is different from the above studies. Particularly, the authors used the RULA methodology to identify and analyse the poor postures used during the performance of various municipal solid waste management activities. The analysis involves systematically observing work activities of the study participants and assigning risk scores on the postures used (McAtamney \& Corlett, 1993). Systematic observation methods can provide particular information about postures and suggestions to rectify them before onset of discomfort (Branson et al., 2002). Rectifying poor postures before the onset of WRMDs is indeed a 
proactive rather than reactive approach and is the essence of primary prevention. Further, RULA is a validated postural method for rapid upper limbs assessment (McAtamney \& Corlett, 1993; Öztürk \& Esin, 2011). Thus, it can yield more reliable findings than unvalidated methods. Moreover, the RULA methodology is useful for quickly screening worker exposures which contribute to disorders of the upper limbs (Öztürk \& Esin, 2011). Furthermore, it is relatively easy to use when one has undergone brief training on its application (Chen et al., 2013). To the best of the authors' knowledge, very few studies have applied direct observation methods such as the RULA in the real life work activities of MSWHs. Yet the RULA method has been demonstrated to be valuable in identifying priority work postures requiring correction (McAtamney \& Corlett, 1993; Öztürk \& Esin, 2011).

Some developed countries now use underground waste depots and automated waste loading mechanisms (Kuijer \& Frings-Dresen, 2004). For underground depots it is not MSWHs who carry and empty refuse bins but citizens. In automated loading, bins are mechanically lifted and emptied into a truck. The physical job demands of waste collection and emptying are greatly reduced in both of these systems. This limits human risks to musculoskeletal disorders due to poor postures. However, most developing countries rely on manual waste collection systems (Sabde \& Zodpey, 2008; Jayakrishnan, Jeeja, \& Bhaskar, 2013), which may contribute to WRMDs due to use of unsafe postures. An investigation to identify such postures may inform waste managers on required interventions to safeguard the occupational health of MSWHs. Therefore, the present study conducted a postural analysis of MSWHs using the RULA methodology.

\section{Methods}

\subsection{Study Design}

A cross-sectional design was conducted among MSWHs of Beitbridge Town Council (BTC) and a reference group of HGHs, in the period April to June, 2016. The protocol used in this study was approved in writing by the Ethics Committee at the University of Pretoria (Ref. 343/2014) and the BTC. A two-way dialogue was held with the 60 study participants where the purposes and procedures of the study were discussed. Participants voluntarily signed informed consent forms with the full rights to withdraw from the study without having to give any excuse. There were no facial identities of participants on all photographs that were taken. The study participants were selected using purposive sampling. The inclusion criteria considered MSWHs and HGHs: (1) whose job description entailed lifting, carrying, pulling, pushing and emptying activities, (2) with at least one year work experience and (3) without known pain related medical conditions which may influence postures, such as arthritis and injuries. The study did not exclude participants on the basis of sex, race or other discriminatory variables and no financial reward was paid for participation. The ages of MSWHs ranged from 27 to 44 years ( $32.97 \pm 4.6$ years). They had a mean weight $68 \pm 2.88 \mathrm{Kg}$ and a mean height of $163 \pm 4 \mathrm{~cm}$. Ages of the HGHs were from 25 to 43 years $(32.40 \pm 4.2$ years), mean weight of $67.50 \pm 2.70 \mathrm{Kg}$ and mean height $1.64 \pm 4 \mathrm{~cm}$. The differences in the age, weight and height of participants were not statistically different $(\mathrm{p}>0.05)$.

\subsection{Walk-Through Surveys and Direct Observations}

Several field visits were done to identify the study participants' work activities deserving inclusion in the RULA postural analysis. We prioritised activities which were routinely done whilst adopting poor postures. Such postures included bending of the neck, trunk, wrist and elevation of the lower and upper arms. Six main activities done by both MSWHs and HGHs were selected for the postural analysis: (1) lifting, (2) carrying, (3) emptying, (4) pushing, (5) pulling and (6) standing. HGHs were used as a reference group in this study because they have considerable commonalities to MSWHs, but they do not handle municipal solid waste. Firstly, the job activities of both HGHs and MSWHs are predominantly performed manually and are physically demanding. For example, HGHs routinely lift patients' meal trays and medical waste bins in hospitals whilst MSWHs routinely lift non-medical waste bins from various waste generation sources such as residences, commercial premises and institutions. The HGHs carry and empty the medical waste bins into the hospital incinerator whilst MSWHs carry and empty the non-medical waste bins into municipal solid waste collection vehicles. Secondly, both MSWHs and HGHs' work entails adopting body positions which involve bending of the upper limbs' joints, which can be analysed using the RULA method to identify unsafe postures and suggest the required corrective interventions.

\subsection{Posture Measurement}

The RULA method was used to assess the work postures of each MSWH and HGH, in their work situations. It uses posture scores. For instance, a score of 1 for the upper arm is awarded when it is near neutral $\left(<20^{\circ}\right.$ abduction) or in a neutral position. The RULA scores were obtained using the standard methods described in literature (McAtamney \& Corlett, 1993; Öztürk \& Esin, 2011; Mukhopadhyay \& Khan, 2015). Notably the final RULA scores are interpreted as follows: 1- 2 negligible risk, 3 - 4 low risk and change may be required, 5 - 6 medium risk, 
further investigation and change soon and $6+$ very high risk, change required now. The photographs of participants at work were taken during their normal working hours. These were used to score the work postures. For each participant, the left and right side of the upper body were rated separately taking note of the angles at the upper limbs joints, the twist of the wrist, neck and trunk as well as abduction of the shoulders. The ratings were used to obtain the final RULA score for each participant.

\subsection{Statistical Analysis}

Data on the postural mean RULA scores were tested for normality using the Shapiro-Wilk test. The data were not normal. The Q-Q plots for the mean RULA postural scores on each activity were scattered in manner resembling a sigmoid shape. Hence, parametric tests such as t-tests could not be done. Thus, a non-parametric test, the Wilcoxon rank sum test (Mann-Whitney test) was performed. All analyses were performed using STATA version 13 at 95\% level of confidence $(\mathrm{p}<0.05)$. The lack of normality could be due to discrete postural risk scores of each worker and the use of relatively small sample sizes of 30 MSWHs and 30 HGHs.

\section{Results}

Table 1 depicts the mean postural scores of MSWHs and HGHs. LHS stands for Left hand side and RHS for right hand side, of the body. The results in this table show significant differences $(p<0.05)$ for the lifting, carrying and emptying activities. Particularly, the postural mean scores of MSWHs on these activities were unsafe as they are above the low risk category of 3-4 rating. They require urgent corrective changes and further investigations (McAtamney \& Corlett, 1993; Öztürk \& Esin, 2011). In lifting the refuse bins trunk severe flexion $\left(20-60^{0}\right)$ was commonly practised. The refuse bins were quickly and forcefully lifted, the neck flexed $\left(>20^{\circ}\right)$, and without prior efforts to first maintain a safe posture and reaching out distance. The postural scores of HGHs were lower than of MSWHs and were mainly in the low risk category. For both MSWHs and HGHs, the mean postural scores for pushing, pulling and standing activities were mainly in the low risk class and not statistically significant $(p>0.05)$.

Table 1. Postural analysis for MSWHs and HGHs (Mean in terms of standard errors, SE)

Mean RULA scores

\begin{tabular}{lllll}
\hline Activity & MSWHs $(\mathrm{n}=30)$ & HGHs $(\mathrm{n}=30)$ & $\mathrm{Z}$ & P-value \\
\hline Lifting RHS & $5.87 \pm 0.19$ & $3.7 \pm 0.21$ & 5.54 & $0.0001^{*}$ \\
Lifting LHS & $6.5 \pm 0.15$ & $4.17 \pm 0.25$ & 5.29 & $0.0001^{*}$ \\
Carrying RHS & $5.17 \pm 0.19$ & $3.73 \pm 0.22$ & 4.67 & $0.0001^{*}$ \\
Carrying LHS & $4.9 \pm 0.21$ & $3.73 \pm 0.22$ & 3.92 & $0.0001^{*}$ \\
Emptying RHS & $5.53 \pm 0.26$ & $4.2 \pm 0.26$ & 3.30 & $0.0010^{*}$ \\
Emptying LHS & $4 \pm 0.25$ & $3.5 \pm 0.21$ & 3.32 & $0.0009^{*}$ \\
Pushing RHS & $2.67 \pm 0.20$ & $3.13 \pm 0.67$ & -1.36 & 0.17 \\
Pushing LHS & $3.13 \pm 0.06$ & $3.13 \pm 0.10$ & 0.80 & 0.43 \\
Pulling RHS & $3.23 \pm 0.11$ & $3.13 \pm 0.06$ & 0.41 & 0.68 \\
Pulling LHS & $3.2 \pm 0.09$ & $3.17 \pm 0.08$ & 0.35 & 0.73 \\
Standing RHS & $3.5 \pm 0.23$ & $3.17 \pm 0.07$ & 0.54 & 0.59 \\
Standing LHS & $3.23 \pm 0.18$ & $3.17 \pm 0.07$ & -0.27 & 0.79 \\
\hline
\end{tabular}

* Statistically significant at $\mathrm{p}<0.05$,RULA scores interpretation (McAtamney \& Corlett, 1993): 1 - 2 negligible risk, 3 - 4 low risk, change may be required, 5 - 6 medium risk, further investigation and change soon, $6+$ very high risk, change required now.

Figure 1 shows a MSWH (A) with a colleague, emptying a refuse bin into a non-compactor vehicle at a height $>$ $1.5 \mathrm{~m}$. The neck is bent in flexion and side-twisted, the trunk severely bent in extension $\left(20-60^{\circ}\right)$, the right shoulder is raised, and the right upper arm is abducted $\left(>90^{\circ}\right)$ whilst manually emptying a load more than $100 \mathrm{Kg}$ above shoulder height in a static posture.For both workers (Figure 1) the right hand wrist is bent in extension $\left(>15^{\circ}\right)$ whilst supporting a heavy load. In figure 1, there is severe physical loading of the MSWHs' shoulders particularly from three key sources: (1) weight of the elevated upper and lower arms, (2) the metal bin and (3) the waste itself. Such poor postures when lifting, carrying and emptying heavy refuse bins contributed to high RULA scores for MSWHs (Table 1). 


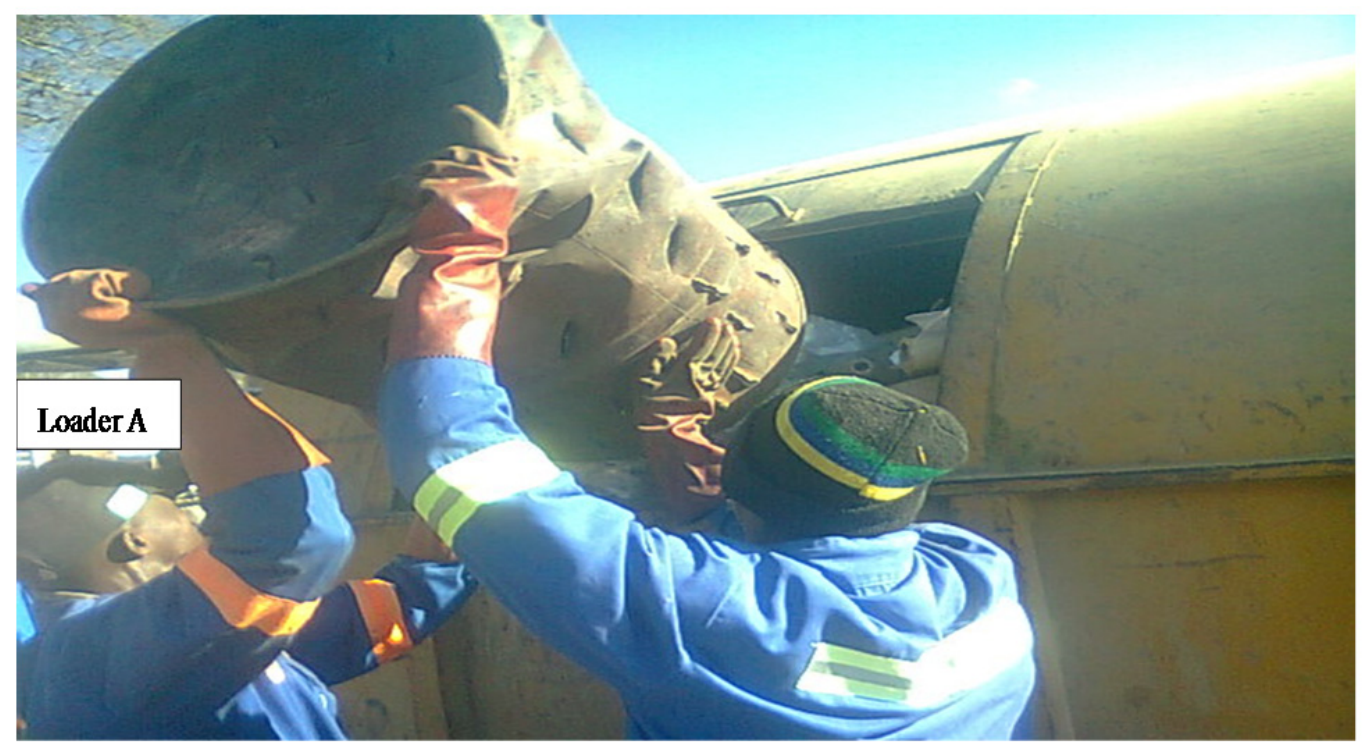

Figure 1. Loader (A) neck side-bending in extension and twisted, trunk in extension $\left(20^{\circ}-60^{\circ}\right)$, right shoulder raised, right upper arm abducted $\left(>90^{\circ}\right)$ whilst manually emptying load $>100 \mathrm{Kg}$ above shoulder height

Although the mean RULA scores for standing were in the low risk category (Table 1), we observed extreme cases that require corrective measures particularly for MSWHs of automated self-compacting vehicles (Figure 2).In Figure 2, the worker is standing in an awkward position whilst at the rear of a moving automated compactor truck. Notably, there is severe trunk flexion $\left(>60^{\circ}\right)$, neck flexion $\left(>20^{\circ}\right)$ and neck slight bending to the right. Also, the right upper arm is in a prolonged, abducted and stressful position. The right shoulder is raised. The legs and feet are not supported but almost resting on toes even though the worker is not wearing slippery-resistant footwear, whilst on smooth and slippery metallic floors.

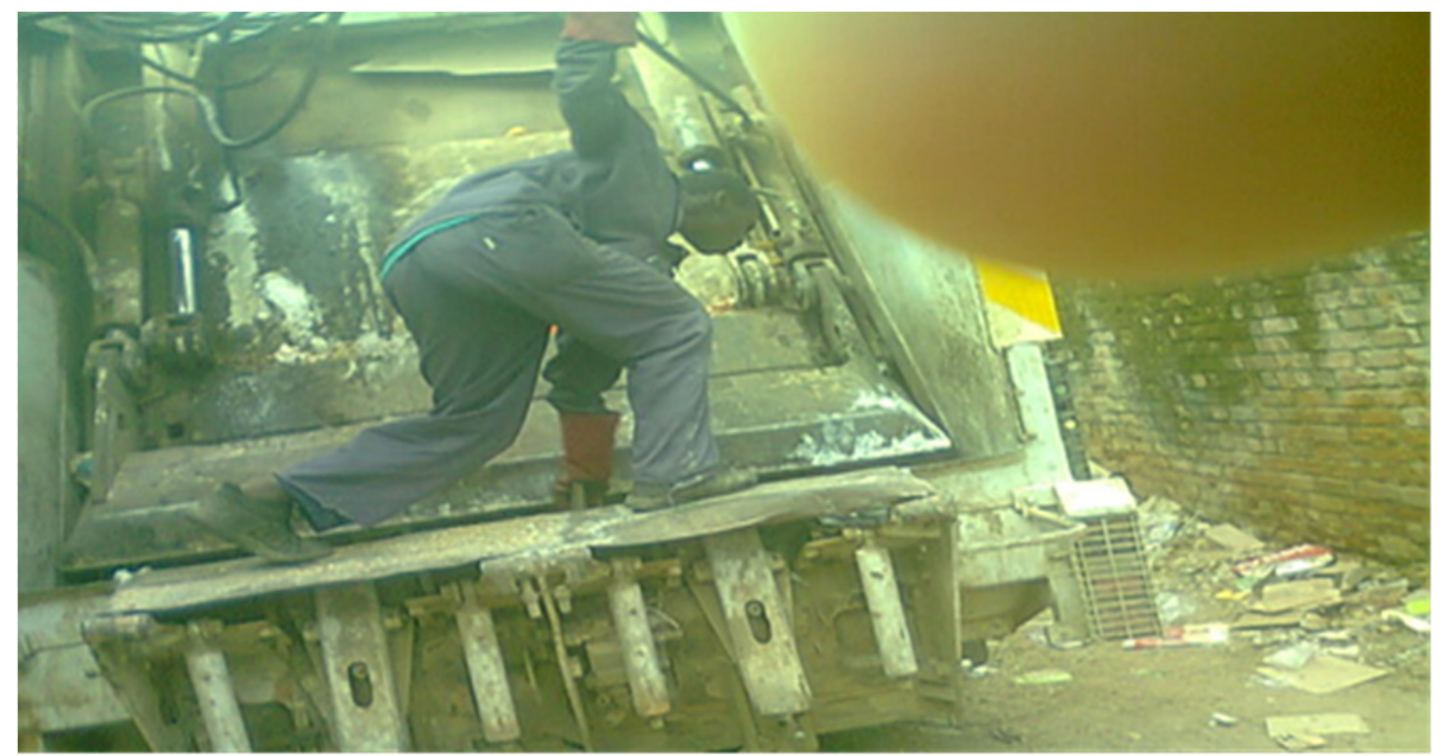

Figure 2. MSWH in poor standing posture: Trunk bent $>60^{\circ}$, right shoulder raised, upper arm (right) abducted, left foot imbalanced whilst inside loading bay of a moving automatic compactor

\section{Discussion}

The section presents a discussion of the present study's results on the postural analysis of MSWHs and HGHs using the RULA methodology. It outlines the implications of the findings with regard to the risk developing of 
WRMDs. It also provides suggestions for improvement, the strengths and limitations of the present study.

\subsection{MSWHs' Postural Risk Scores}

There are a number of crucial findings on MSWHs which deserve highlighting. The mean postural RULA risk scores exceeded the low risk category of 3-4 with regard to lifting, carrying and emptying refuse bins. Such scores are unsafe and require urgent corrective changes and further investigations (McAtamney \& Corlett, 1993; Öztürk $\&$ Esin, 2011). The corrective changes should focus on the poor working postures in the upper limbs which include: i) excessive trunk bending $\left(20-60^{\circ}\right)$, ii) neck flexion $\left(>20^{\circ}\right)$, iii) sustained shoulder raising, iv) abduction of upper arms $\left(>90^{\circ}\right)$ and v) wrist bending in extension (>15). Kuijer \& Frings-Dresen (2004) describe two possible measures which may limit the manual lifting, carrying and emptying activities, thus address some of the poor postures observed in the present study. The measures are: i) adoption of underground depots where citizens deposit their waste rather than MSWHs and ii) mechanising the waste collection activities. However, such measures may present new risks to MSWHs (Kuijer \& Frings-Dresen, 2004). Moreover, the financial challenges of most developing countries may limit the adoption of such measures. This challenge suggests the need for such nations to prioritise some low-cost interventions such as postural competency based training to correct the poor postures employed in the lifting, carrying and emptying activities. Such training may empower MSWHs with knowledge and skills for safely performing the activities.

Further, the present study's findings on postural deficits of MSWHs are suggestive of an elevated risk to developing WRMDs. Poor working postures have associated with the risk of developing WRMDs in previous studies (Dianat \& Salimi, 2014; Kaliniene et al, 2016). Particularly, non-neutral trunk postures have been associated with low back pain (Rosecrance, Rodgers \& Merlino, 2006), shoulder abduction with shoulder pain, (Punnet et al., 2000; Svendsen et al., 2004) and neck twist and flexion with neck pain (Ariëns et al., 2001). Kaliniene and colleagues (2016) conducted a cross-sectional investigation of musculoskeletal disorders and occupational factors among computers users. They found that participants reporting musculoskeletal disorders had high mean RULA scores that were statistically significant. They also reported a positive association between experiencing wrist/hand pain and high quantitative work demands. Kaliniene et al (2016) also observed that an increase in RULA scores by a point corresponded to an increased probability of having complaints of the wrist/hand, upper and low back pain. In the present study, lifting, carrying and emptying refuse bins by MSWHs had high mean RULA postural scores which were statistically significant in comparison to those of HGHs. Thus evidence from Kaliniene and colleagues' suggests that the high postural RULA scores of MSWHs with regard to lifting, carrying and emptying activities, may predispose these workers to WRMDs. This suggests that in the long term, waste managers may need to phase out manual lifting, carrying and emptying of refuse bins in favour of mechanically lifted and emptied bins, in order to reduce the risk of developing WRMDs in this group of workers. Also, task performance supervision and safety training with demonstrations on the desirable work postures maybe adopted.

In the United States, Cakit (2015) applied RULA in a laboratory setup. The participants were non-MSWHs performing refuse bin lifting and dumping (emptying) activities. The findings showed high RULA scores for the activities. The similarity of the findings between this laboratory study and our field based investigation suggests that despite the differences in design, the two studies are mutually complementary.

\subsection{HGH's Postural Risk Scores}

The study's results indicate that HGHs' mean postural risk scores were mainly in the low risk category and were significantly different $(\mathrm{p}<0.05)$ compared to MSWHs for the lifting, carrying and emptying work activities. Thus, the HGHs used safe postures at the upper limbs in comparison to MSWHs. Such safe postures are suggestive of a low risk to developing WRMDs. The mean postural RULA scores of HGHs and MSWHs with regard to pulling, pushing and standing activities were low and not statistically significant $(\mathrm{p}<0.05)$. Some authors associated these activities with less biomechanical load on the trunk (Schibye et al., 2001; Kuijer et al.; 2003). In light of this, pushing and pulling activities seem to pose a low risk of progressing to WRMDs. Thus, it appears safer for managers of HGHs and MSWHs to promote wide usage of pushed or pulled bins than manually lifted and carried ones.

\subsection{Strengths and Limitations}

There some strengths and limitations of this study. One of its main strengths is the utilisation of a validated method for data collection. A validated tool may offer better opportunities to provide valid and reliable findings compared to subjective tools like questionnaires, which may introduce biases from the respondents' verbal reports. Also, this study managed to identify and analyse risk levels of priority work activities performed using poor postures. These 
are lifting, carrying and emptying of refuse bins. The findings have practical implications to the organisation of municipal solid waste handling activities. Particularly, the evidence of elevated postural scores when performing these activities suggests that corrective measures are urgently required to safeguard MSWHs from WRMDs. A major limitation of this study is that it is a single centre cross-sectional study. This may limit the capacity to generalise the findings to waste management situations in other local government structures. Further work may consider using multi-centre longitudinal studies. Furthermore, although both MSWHs and HGHs performed similar work activities in the present study, some characteristics of their work settings are slightly different. For example HGHs' work is predominantly performed indoors whilst that of MSWHs is primarily done outdoors. Previous literature has associated outdoor activities with greater occupational exposure to ultra-violet radiation (Knibs, 2014; Ncube, Ncube, \& Voyi, 2017) and low temperatures (Knibs, 2014), which may affect the level of physical exhaustion and the postures used. Thus, the differences in the occupational settings may limit the capacity of the present study to draw completely comparable conclusions on MSWHs and the reference group. Another limitation relates to the possibility of selection bias since the study used a non-random method: purposive sampling to enrol the participants. Future studies may consider replicating the present study's findings using random sampling methods.

\section{Conclusion}

Overall, results of the present study show higher RULA postural scores to MSWHs with regard lifting, carrying and emptying of refuse bins. Such scores may contribute to an elevated risk of developing WRMDs in these workers compared to the reference group. This suggests that waste managers need to prioritise interventions such as adopting mechanically lifted and emptied bins, conducting safety training for MSWHs and task performance supervision, so as to reduce the risk of developing WRMDs.

\section{Acknowledgments}

The study was self-funded. The authors would like to thank the study participants for their valuable time and input. The services of Artwell Kanda with regard to editing and proof reading the article are greatly appreciated.

\section{Competing Interests Statement}

The authors declare that they has no competing or potential conflicts of interest.

\section{References}

Alexopoulos, E. C., Stathi, I. C., \& Charizani, F. (2004). Prevalence of musculoskeletal disorders in dentists. BMC Musculoskeletal disorders, 5, 16. https://doi.org/10.1186/1471-2474-5-16

Ariëns, G. A. M., Bongers, P. M., Douwes, M., Miedema, M. C., Hoogendoorn, W. E., van der Wal, G., . . van Mechelen, W. (2001). Are neck flexion, neck rotation, and sitting at work risk factors for neck pain? Results of a prospective cohort study. Occup Environ Med, 58, 200-207. https://doi.org/10.1136/oem.58.3.200

Branson, B. G., Williams, K. B., Bray, K. K., Mcllnay, S. L., \& Dick, D. (2002). Validity and reliability of a dental operator posture assessment instrument. Journal of Dental Hygiene, 76(4), 255-261.

Catkit, E. (2015). Assessment of the physical demands of waste collection tasks. Global Nest Journal, 17(2), 426-438.

Chen, J., Falmer, T., Parsons, R., Buzard, J., \& Ciccarelli, M. (2013). Impact of experience when using the rapid upper limb assessment to assess postural risk in children using information and communication technologies. Applied Ergonomics, 45(3), 398-405.https://doi.org/10.1016/j.apergo.2013.05.004

Dianat, I., \& Salimi, A. (2014). Working conditions of Iranian hand-sewn shoe workers and associations with musculoskeletal symptoms. Ergonomics. https://doi.org/10.1080/00140139.2014.891053

Holmberg, S., Thelin, A., Stiernström, E. L., \& Svärdsudd, K. (2003). The impact of physical work exposure on musculoskeletal symptoms among farmers and rural non-farmers. Ann Agric Environ Med, 10, 179-84. Retrieved from https://www.ncbi.nlm.nih.gov/pubmed?term=holmberg\%20s\%202003\%20179-84

Hoozemans, M. J. M., Kuijer, P. P. F. M., Kingma, I., van Dieën J. H, de Vries, W. H. A., van der Woude, L. H. V . . . \& Frings-Dresen, M. H. W. (2004). Mechanical loading of the low back and shoulders during pushing and pulling activities. Ergonomics, 47(1), 1-18. https://doi.org/10.1080/00140130310001593577

Howarth, S. J., Grondin, D. E., La Delfa, N. J., Cox, J., \& Potvin, J. R. (2016). Working position influences the biochemical demands on the low back during dental hygiene. Ergonomics, 59(4), 545-555. https://doi.org/10.1080/00140139.2015.1077274 
Jayakrishnan, T., Jeeja, M. C., \& Bhaskar, R. (2013). Occupational health problems of municipal solid waste management workers in India. Int J Env Health Eng, 2, 42. https://doi.org/10.4103/2277-9183.122430

Kaliniene, G., Ustinaviciene, R., Skemiene, L., Vaiciulis, V., \& Vasilavicius, P. (2016). Associations between musculoskeletal pain and work-related factors among public service sector computer workers in Kaunas County, Lithuania. BMC Musculoskeletal Disorders, 17, 420. https://doi.org/10.1186/s12891-016-1281-7

Knibbs, L. D. (2014). Occupational hazards to the health of professional gardeners. International Journal of Environmental Health Research, 24(6), 580-589. https://doi.org/10.1080/09603123.2014.883594

Kuijer, P. P. F. M., \& Frings-Dresen., M. H. W. (2004). World at work: Refuse collectors. Occup Environ Med, 61(3), 282- 286. https://doi.org/10.1136/oem.2002.001172

Kuijer, P. P. F. M., Hoozemans, M. J. M., Kingma, I., Van Dieen, J. H., De Vries, W. H. K., Veege, D. J. H . . \& Frigns-Dresen, M. H. W. (2003). Effect of a redesigned two-wheeled container for refuse collecting on mechanical loading of low back and shoulders. Ergonomics, 46, 543-60. https://doi.org/10.1080/0014013031000065619

Liu, C. W., Chen, T. W., Wang, M. C., Chen, C. H., Lee, C L., \& Huang, M. H. (2003). Relationship between carpal tunnel syndrome and wrist angle in computer workers. Kaohsiung J Med Sci, 19(12), 617-23. https://doi.org/10.1016/S1607-551X(09)70515-7

Malińska, M., \& Bugajska, J. (2010). The influence of occupational and non-occupational factors on the prevalence of musculoskeletal complaints in users of portable computers. International Journal of Occupational Safety and Ergonomics, 16(3), 337- 343. https://doi.org/10.1080/10803548.2010.11076850

McAtamney, L., \& Corlett, E. N. (1993). RULA: a survey method for the investigation of work-related upper limb disorders. Appl Ergon, 24(2), 91-99. https://doi.org/10.1016/0003-6870(93)90080-S

Rosecrance, J., Rodgers, G., \& Merlino, L. (2006). Low back pain and musculoskeletal symptoms among Kansas farmers. Am J Ind Med, 49(7), 547-56.https://doi.org/10.1002/ajim.20324

Mukhopadhyay, P., \& Khan, A. (2015). The evaluation of ergonomic risk factors among meat cutters working in Jabalpur, India. Int J Occup and Environ Health, 21(3), 192198.https://doi.org/10.1179/2049396714Y.0000000064

Ncube, F., Ncube, E. J., \&Voyi, K. (2017). Bioaerosols, noise and ultraviolet radiation exposures for municipal solid waste handlers. Journal of Environmental and Public Health. https://doi.org/10.1155/2017/3081638.

Öztürk, N., \& Esin, M. N. (2011). Investigation of musculoskeletal symptoms and ergonomic risk factors among female sewing machine operators in Turkey. International Journal of Industrial Ergonomics, 41, 585-591. https://doi.org/10.1016/j.ergon.2011.07.001

Punnett, L., Fine, L. J., Keyserling, W. M., Herrin, G. D., \& Chaffin, D. B. (2000). Shoulder disorders and postural stress in automobile assembly work. Scand $J$ Work Environ Health, 26(4), 283-91.https://doi.org/10.5271/sjweh.544

Sabde, Y. D., \& Zodpey, S. P. (2008). Respiratory morbidity among street sweepers at Hanumannagar Zone of Nagpur Municipal Corporation, Maharashtra. Indian J Public Health, 52(3), 147- 9.

Schibye, B., Sogaard, K., \& Martinsen, D. (2000). Mechanical load on the low back and shoulders during pushing and pulling of two-wheeled waste containers compared with lifting and carrying of bags and bins. Clin Biomech, 16, 549-59. https://doi.org/10.1136/bmjopen-2012-001338

Svendsen, S. W., Bonde, J. P., Mathiassen, S. E., Stengaard-Pederson, K., \& Frich, L. H. (2004). Work related shoulder disorders: quantitative exposure-response relations with reference to arm posture. Occup Environ Med, 61(10), 844-853. https://doi.org/10.1136/oem.2003.010637

Valachi. B., \& Valachi, K. (2003). Mechanisms leading to musculoskeletal disorders in dentistry. J Am Dent Assoc., 134(10), 1344-50. https://doi.org/10.14219/jada.archive.2003.0048

\section{Copyrights}

Copyright for this article is retained by the author(s), with first publication rights granted to the journal.

This is an open-access article distributed under the terms and conditions of the Creative Commons Attribution license (http://creativecommons.org/licenses/by/4.0/). 